\title{
Eco-Cultural Determinants and Personality Development of Children with Visually Impaired, Kumbo Central Sub-Division; North West Region of Cameroon
}

\author{
Tani Emmanuel Lukong ${ }^{1 *}$, Ph.D, Sr. Therese NyiaNjamfa ${ }^{2}$, Ph.D, Nformi Doris Jaja ${ }^{3}$ \\ ${ }^{1}$ University of Buea and Meridian Global University (MGU), Cameroon \\ ${ }^{2}$ Catholic University of Cameroon (CATUC), Bamenda \\ ${ }^{3}$ Master's Student, Department of Educational Psychology
}

\author{
"Corresponding Author: Tani Emmanuel Lukong, Ph.D, University of Buea and Meridian Global \\ University (MGU), Cameroon
}

\begin{abstract}
A child's socialization and development processes are contextual and cultural. In the typical African society, children are brought up under strict norms and belief systems. Whether a child becomes outgoing or shy, intellectually advanced or average, or energetic or subdued depends on many unique influences whose effects are difficult to predict at the child's birth. A variety of factors influences child development. Heredity guides every aspect of physical, cognitive, social, emotional, and personality development. Family members, peer groups, the school environment, and the community influence how children think, socialize, and become self-aware. This descriptive survey study explored the socio-cultural determinants on personality development of visually impaired children in Kumbo central-Sub-Division. The triangulation method was used. The study was based on the framework that the proactive effects of good parent-child interaction, peer interaction and cultural respect for disabilities could help enhance personality development of visually impaired children, to stabilize their impairments, improve adherence to psychosocial treatment, and promote progress toward socialization and improvement. The study utilized 66 children/students with visual impairments with their categories ranging from mild to profound. Respondents were randomly selected from five schools, which included Baptist Rehabilitation Centre for the Blind, Government Bilingual High School Kumbo, Chaffee Memorial College Kumbo, and City College Kumbo. The students were between 12-21 years old. Data were obtained through questionnaires, non-participant observation and most importantly, focus group discussion was conducted among 48 parents of children with and without visual impairments in six sessions representing different areas and income groups. After a comprehensive research the factors that were identified as important determinants of child personality are parent's economic conditions, their education level, family size, family structure, children's socialization level, peer group, school environment, parents' involvement level in children's day-to-day activities, and cultural beliefs attribute to visual impairment. The quantitative data were subjected to descriptive and inferential statistical analysis using the chi square test to test the hypotheses. Descriptive statistics were used to present the distribution of subjects between and within subsets using frequencies, proportions and multiple response sets. The major findings obtained were: Students/children with visual impairments development of positive self-esteem relied heavily on their interaction with their parents (calculated value $\left(x^{2}=103.333\right)$ was greater than the table value $\left(x^{2}=32.67\right)$. Students/children with visual impairments will develop good self-efficacy if their interaction with peers is enhanced through reflective friendship (calculated value $\left(x^{2}=249.09\right)$ was greater than the table value $\left(x^{2}=23.68\right)$. The self-concept of Students/children with visual impairments depends on cultural respect and perception of who visually impaired children are. The calculated value $\left(x^{2}=181.879\right)$ was greater than the table value $\left(x^{2}=23.68\right)$ On the basis of the findings of the study, some recommendations are proposed, focusing on parents' reasonability towards child education and socialization, improving parent, teacher and children relationships. This study also highlighted and suggested areas of further research. Moreover, the role of media and other new emerging sources of mass communication should also be investigated. More studies on children's psychology give understanding to better personality development.
\end{abstract}

Keywords: Socio-Cultural Determinants, Personality Development, Visually Impaired

\section{INTRODUCTION}

Children are more than the object of their parents' attention and love; they are also a biological and social necessity. The human species perpetuates itself through children; cultural, religious and 
national groups that transmit their values and traditions through children; families maintain their lineage through children; and individuals pass on their genetic and social heritage through children. The ultimate value of children is the continuity of humanity (Arnold et al, 1975). This study was aimed at examining the socio-cultural determinants on personality development of children (adolescents) with visual impairments in Kumbo Central Sub-Division. It sought to establish whether socio-cultural context can make or mar children personality development. Though Cameroon like other African countries practice a culture of collectivism, there is no doubt that within the Cameroon context diversity in cultural manifestation does exist. This cultural diversity has a lot of implications for the personality development of children especially those with disabilities. Socio-cultural factors which this study focused attention to include: parent-child interaction, peer interaction, cultural respect for disabilities and societal acceptance. Other variables such as Family structure, family size, parental educational level and residential area (environment). These conglomerated to synthesize the problem under investigation.

\section{BACKGROUND OF THE STUDY}

Some special needs children with talents in Cameroon and indeed the world over have lived and died without education. Many have also lived and died, unknown and perhaps unwanted, their talents lost of the detriment of the society (Abang, 1981). As it is the case in most developing countries, effective participation of all able bodied individuals is required for the building and total transformation of their respective societies. This expectation is a bit difficult for persons with special needs due to their handicapping conditions. Educators and laymen alike having recognized the special needs of such children, youths and adults, have designed a number of programs (educational and non educational) to give appropriate assistance in a variety of ways. Traditional beliefs, customs and attitudes held by different ethnic groups in Cameroon have for a long time influenced the education and socialization of persons with special educational needs, Yuh\&Shey (2008). In some parts of the country, children with disabilities were and are still denied their basic rights especially the right to go to school, communicate and interact with peers in spite of global movement towards universalization of access to schooling for all children (world's conference on education for all, Jomtien, Thailand, 1990; Salamanca conference on special need education, Spain 1994; millennium development goals, 2000). The right to education is clearly stated in the Universal Declaration of human rights (UNESCO, 1946); "everyone has a right to education". The participants in the world's conference on education for all re-affirmed the right of all people to education, particularly, Basic education.

$W e$, the participants in the world's conference on education for all, reaffirm the right of all people for education. This is the foundation of our determination, singly and together, to ensure education for all... together we call on government, concerned organization and individuals to join in this urgent undertaking. The basic learning needs of all can and must be made...we adopt, therefore, this world's Declaration on education for all; Meeting Basic Learning Needs and agree on the framework for Action to Meet Basic needs, to achieve the goals set forth in this declaration.

The Salamanca conference on 'Special Needs Education' held in June 1994 emphasized the need for policy change in the education of people with disabilities. The second goal in the Millennium Development Goal (MDGs) outlined in the "Millennium Declaration" of September 2000, focuses on 'Achieving universal primary education'. Special education in Cameroon began in informal settings, especially in the family circles where some parents and family members of persons with disabilities tried to teach their children like skills, for example, showing the blind child how to wash its hands, and how to move around the home; making signs to a deaf child when communicating with it. Teaching all the children how to count in their local dialects and the use of local currency in buying and selling was also the pre-occupation of most parents in the early days in Cameroon. The education of children with disabilities in the pre-colonial and colonial period indicates a slow yet steady recognition of the plight encountered by persons with special needs. The British Baptist Missionary Society first introduced western education in Cameroon in 1842. The number of schools remained with few Cameroonians gaining access to formal education. Catholic and Presbyterian missionary societies, like the Pallotine Fathers, the Mill Hill missionaries and the Basel Mission also made 
substantial contribution to formal education. By the time German colonial rule was established after 1884, there were already a few Cameroonians who had been educated by the missionaries. With the introduction of Christian education by western missionaries, consideration was given to the well being of persons with disabilities. A small number of children were admitted in mission schools and were taught alongside other children.

Nsamenang (1996) in his sketch in a proposed study of disabilities in Cameroon, points out that historically education and care for children with disabilities was rooted in the community, church and charitable organizations. He argues that these services were organized as a protection consideration, and as an attempt to provide services which public education and training systems were unable to offer. Before 1975, the welfare of persons with disabilities in Cameroon was the responsibility of a unit in the ministry of Health. As a matter of fact and misconception, disability was perceived as a disease and sometimes seen as incurable. The question that most people asked was: How can people who are sick and cannot be cured go to school? Formal education for children and young adults with disabilities was done mostly in specialized centres with very few attending regular primary schools. The first centre created in 1972 called "ecolespecialise pour EnfantsDeficientsAuditif-ESEDA (special school for children with Hearing Impairments), Yaounde and L'externat MedicoPedagogigue-LA COLOMBRE (special school for mentally retarded) Yaounde. These centres were run and managed by religious groups and parents of children with disabilities

On the $15^{\text {th }}$ August, 1975 another centre called promhandicam was created in Yaounde by Italian missionaries. This centre has as its main aim the vocational training of children and young adults with disabilities for their eventual socio-economic integration in the society. With the creation of the Ministry of Social Affairs in 1975, a Department of National Solidarity was established to oversee the well being of persons with disabilities and the very old. This department, in collaboration with the Ministries of Education has put in some efforts to improve the education of persons with disabilities. Thus, the creation of many privately owned special schools or institution in almost all provinces of the country with some receiving yearly subsidies from the state took effect. Some of these institutions or special schools serve persons with specific disabilities, for example, those with mental retardation, visual and hearing impairments, behavioural disorders, and so on. Others provide services to persons with multiple disabilities. To train young Cameroonians with visual impairments in arts and crafts, the ministry of Social Affairs created the Rehabilitation Institute for the Blind (RIB) popularly known as Bulu Centre for the Blind in Buea. This was the first institution for persons with disabilities created by the government in Cameroon in 1973. It is under the control of the Ministry of Social Affairs. More private institutions have been established in recent years, but most of them are in urban areas. It is worth noting that nearly all these institutions, whether owned by government, Mission or NGOs have problems of shortage of trained and qualified staff and personnel to serve the persons with disabilities. (AJS, 2008)

Legislation and policy on education of persons with disabilities lack a lot of reinforcement, which could help in the remediation of their day to day problems. The only Law in Cameroon, which addresses the needs of persons with disabilities, is law No. 83/13 of July, 1983 relating to the protection of persons with disabilities. The conditions for implementing this law are laid down in decree No.90/1516 of 26 November, 1990. These two documents form a foundation stone for a strong government policy toward the education of persons with disabilities. Article 3 of law No. 83/13 of July 1983 focuses on the education of children with disabilities. Three options are given concerning the type of education to be given this group of children.

These include:

a) Integration in ordinary schools: parents of children with disabilities are advised to send them to regular schools. This integrated approach calls for specialized staff to be recruited to serve the needs of children with disabilities in regular schools, and also the provision of appropriate pedagogic material.

b) Admission in special classes: some parents who seek admission for children with disabilities in regular schools are advised to place them in special classes. This is seen as a temporary solution 
in the sense that the specialized training adapted to the child's ability in such classes only prepares him/her for eventual admission in a regular class.

c) Admission in specialized institutions: in this case, the child with disability is admitted in a specialized institution where he/she receives special education as well as medical care and treatment.

Although the law on the protection of persons with disabilities was enacted by Parliament in 1983, the Head of State only signs the decree laying down the modalities of its application in November, 1990. It is divided into five parts with the first part dealing with the education and vocational training of persons with disabilities. Article 1 of this law clearly states " The education of children and young adults with disabilities shall be taken care of in regular and special schools...In case of necessity, regular schools enrolling children with disabilities shall be provided with special teachers and didactic material adapted to the children's needs" (MINAS, 1990). As far as easing access of pupils with disabilities into various classes in ordinary schools is concerned, schools are required to make the necessary adjustments to suit the needs of all children. To ensure the proper digestion of the 1983 law, the Minister of National Education issued circular letter No. 86/1/658/MINEDUC/CTZ of January 13, 1986 calling on all national education authorities to implement the 1983 law by giving priority, easing and facilitation the enrolment of children with disabilities in public and private schools. This circular letter also stated that punishment would be meted out to recalcitrant head teachers and teachers who go against the 1983 law. The major setback witnessed today is lack of follow-up and implementation of this policy. The most recent document on the education in Cameroon is the February 2005 Draft Document from the Technical Committee for the Elaboration of the Sector Wide Approach in education. Although this document reflects a common and coherent vision of education in Cameroon, nothing is mentioned about the education of persons with disabilities.

In Cameroon as in other developing nations, people have displayed little awareness of the etiology of disability. As a result, the concept of rehabilitation and provision of services to persons with special needs have not been fully adopted as a social value. Public attitude towards disability is not encouraging and government is yet to take serious implementation steps in advancing programs for persons with special needs. Although a number of institutions exist to provide education for persons with special needs, not all of these needs are being met (Lukong, 2009). However, in recent times Cameroon government geared up to promote education as the vehicle for all acquisition of knowledge. This has increasingly gained prominence in the agenda of government as a means for the empowerment of her people. This has further informed government's position in the National Policy on Education. In any society, conceptions of disability are undoubtedly influenced by socio-cultural beliefs, assumptions and/or myths and indeed fears prevalent in that particular society. (Groce, 1999, 2000) and (Barnes and Mercer, 2005) contend that understanding traditional beliefs and related practices about disability within a specific socio-cultural context is of vital importance. However, as Sheldon (2005: in Barnes and Mercer, 2005) rightly forewarns, "Indigenous beliefs and attitudes, when described and interpreted by western/western trained researchers often illuminate more about western prejudices and belief systems than they do about the societies of which they claim to be gaining an understanding. Mindful of this potential hazard, in this work, we therefore attempted to carefully explore the impact of traditional/cultural beliefs and practices within the social setting on visually impaired children from a Cameroonian perspective.

The foundation of personality lies in the womb of family. Family is regarded as "nursery of socialization" and is formed in all societies with varying nature and composition. One of the important components of the family system is the parenting style (Lukong, 2009). According to Judith Harris (1998), parents are minor players in children's personality development. The transition to parenthood is an emotionally and physically stressful undertaking but it is also one of the most satisfying and highly valued adult social roles (Cowan and Cowan, 1992). The child uses his parents as models for his adjustment to life and fundamental pattern once estimated at home, cannot be eradicated completely yet modified or changed as the child grows up. Personality is the "quality of individuals' habits of thought and expression, his attitudes and interest, his manner of acting and his personal philosophy of life (Wood Worth, 1997). Personality is the individual's relatively distinct and 
consistent manner of perceiving, thinking, feeling, and behaving. This pattern of existence is sometimes used to infer the fundamental essence of the individual functioning in the physical, psychological, and social worlds (International Encyclopaedia of Sociology, 1995).

The development of personality is conceived primarily as a process of learning which arises when the infant's innate behaviour repertoire is exposed to environmental circumstances. Personality and character develop chiefly during the impressive years. Everyone is born with heredity potential that is shaped and moulded by surroundings or culture. Heredity and environment both play a major part in the development of a person's total personality. Altitudes, habits and interest as well as character and conscience including the morals as spiritual ideas, standards life's values and modes of social expression are all integral parts of personality (Harris, 1995). Children with visual impairments often have difficulty engaging in positive social interactions. They are typically unable to demonstrate peerrelated social competence and, as a result, engage in more solitary play than do their typical peers Guralnick, Connor, Hammond, Gottman, \&Kinnish, (1996a, 1996b) McConnell \& Odom, (1999). Studies have found that children who are visually impaired (that is, have low vision) do not display a full range of play behaviours and demonstrate compromised social interactions Rettig, (1994).

From a historical perspective, disability has been viewed in three main ways, as an individual problem, as a social construction and as a social creation Oliver, (1993). The first view that disability is the individual's problem or personal tragedy derives from the medical model in which children with disabilities were excluded from the mainstream, and placed in segregated settings. Most African cultures attribute supernatural and spiritual forces to disabilities Nsamenang, (1992). Consequently most African families approach disabilities with anxiety and repugnance: no family expects an abnormal or disabled child. The view that disability is an individual's problem that elicits a series of misconceptions, beliefs, fear, is commonplace in professional practice Ballard, (1993). By focusing on disability as an individual problem, educational settings and society had a dominant reason to resist making changes to include people with disabilities. Segregating people with disabilities form their families and the community elicited a response of curiosity, fear, revulsion, guilt and anxiety in the healthy members, which in turn reinforced the perception of disability as a personal tragedy, passivity and dependency Sullivan, (1991).

The second view that disabilities are socially constructed is based on the assumption that if we change the way people think about disability, then we eliminate the problems of disabled people Oliver, (1988). This implies that disabilities can be more or less disabling depending on people with disabilities own attitudes and by the expectations and attitudes of others. The social creationist view shifts "the focus of disability from individuals, and locates it squarely in society and social organizations that discriminate" Suillivan, (1991). Taking a social creativist point of view means that we value disability and that we accept diversity and see the need to incorporate all children, youth and adults as active fully participating members of the community at least in principle.

To conceptualise the range of human abilities and disabilities involves a lot of empirical backings. The concept in itself proves that there are children and persons with disabilities in all parts of the world and at all levels in every society. The number of persons with disabilities in the world is large and is growing United Nations, (1994). Both the causes and the consequences of disability vary throughout the world. Those variations results from different physical conditions, socio-economic circumstances and the different provisions that families and state parties make for the well-being of their members and citizens. In some African countries the percentage of children and people with disabilities is estimated to be very high and growing, being exacerbated by civil war, arms conflict or extreme poverty. For the most part, families of persons with disabilities are extremely poor. Contextualizing human abilities and disabilities, traditional impediments vary in magnitude and the social integration of persons with disability takes different dimensions. In the African context, some cultural norms especially those that arise against the birth of children with disabilities abound and directly or indirectly frustrates the efforts made by modernization. In this view inclusion of persons with disabilities is a no go area. Culture and religious attitudes, understanding and beliefs all play their part in how care is ultimately sought, planned, accepted and delivered. Early research interest focused on the attitude of white middle class parents within a Judaeo-Christian faith. The birth of a child with visual impairments either stimulated a greater faith or resulted in a complete loss of faith. Some believed that they were being punished for their sins. 
Studies indicate that when parents identify disabilities in their children they usually encounter a range of mixed attitudes, emotional reactions and feelings toward their children. Parents may feel inadequate simply for having a child who is not perfect. They may experience guilt, particularly if they have ignored advice to stop smoking, to have an abortion, or to have a child at all at 'this age'. These feelings have both direct and indirect effects in the behaviour and attitude of family members towards the child with disability (Laura Middleton, 1995). Parents often suffer from psychological problems that arise from disabilities of their children. Studies reveal that parents feel insecure and guilt-ridden because of imagined responsibility for the child's condition. They do some sort of searching for shortcomings of their own which might have caused disability in their children. They feel ashamed of their children's backwardness and often try to hide them from friends and neighbours. Through time and after getting more knowledge and experiences with children disabilities, parents face another psychological problem. They feel guilt of not recognizing the problem with the children in time. Parents and their influences on the socialization of the children have been considered as the basis of mainstream psychological theories. In other words, most research regarding parenting behaviours have been initiated by theoretical concerns regarding the role of parents' behaviours on children's socialization and personality development. Equipping children with the necessary means to become a successful member in society have been linked to the adaptive child rearing strategies expressed in the parent-child interaction context Bornstein, (2002). Behaviorist learning theories emphasized the "blank slate" status of infants, and parents were considered as those responsible and have power to train and teach their children what they must learn. For decades, developmental psychologists have been interested in how parents influence their children's development, and one approach in this area is the study of what has been termed as parenting style Darling and Steinberg, (1993).

Parents' values, belief system, and socialization goals are influenced by cultural context Tamminen, (2006). Analogously, parent-child interaction can be quite consistent within a particular cultural context and can change substantially from one context to another. To this extent, what is normal within the bounds of one culture maybe labelled abnormal in others. Some behaviours may be considered normal in one culture and abnormal in others. When parents are exposed to a dominant given culture with high frequency, they are affected by the norms and values of that culture. The childrearing patterns of a culture are the childrearing norms. They include the generally accepted styles and types of care expected of caregivers in responding to the needs of children in their early months and years. The patterns define childrearing in a way that assures the survival, maintenance and development of the group or culture as well as of the child. There are patterns of behaviour surrounding specific times in a child's life. For example, there are expectations in terms of parental and community behaviour in relation to a child's birth. There are norms in relation to how a child is named. There are expectations in terms of how an infant's death is handled. There are expectations in terms of how the child will learn to become a responsible member of the society. While the patterns govern the culture as a whole, these patterns may or may not be followed by individuals; there are variations in the particular circumstances in which a child is raised and individual caregivers differ in their beliefs and knowledge. Sometimes within a culture there is considerable latitude in terms of adherence to cultural patterns. In other instances, deviation leads to ostracism.

The explanation for why particular childrearing practices are used comes from the traditions, myths and the religious systems that underlie the culture. The beliefs are a response to the demands of the culture as well as the needs of individuals. The family and community implement specific childrearing practices which they believe will: Ensure the survival and health of the child, including the development of the child's reproductive capacity to continue the lineage and society. Develop the child's capacity for economic self-maintenance at maturity, to provide security for the elders and younger members of the society. Ensure the survival of the social group by assuring that children assimilate, embody and transmit appropriate social and cultural values to their children. In some instances beliefs evolve as the needs of the people change. In other instances beliefs restrict people's ability to respond to changing conditions. In most societies, the family, however defined, is the primary unit given responsibility for raising children. There is considerable individual variation in practice from family to family, depending on the psychological make-up of the parents, including their own personality, the experiences they had as children, and the conditions under which they are living. The role other members of the society play in the raising of children differs depending on the 
specific cultural group. In some settings community members play a significant role and in others they take on a more distant role. When societies are more or less isolated from one another and there are few outside influences, what one generation passes on is similar to the way the next generation raises its children and there is a relative stability of values, practices and beliefs. While some cultures have remained relatively isolated and intact, there are other cultures which have been more vulnerable to change. This vulnerability is the result of increased exposure to other ideas, sometimes through formal education, and increasingly through mass media. For some societies the introduction of different ideas has resulted in a relatively easy incorporation of the new, with maintenance of the traditional. For others, the juxtaposition of the traditional and the new, along with economic changes which have threatened people's survival, have left cultures disorganized and groups of people at a loss in terms of their values and beliefs. In situating the present study within existing sociological and culturally bound psychological theories, the Ecological theory of Urie Bronfenbrenner, and Erik Erikson Psychosocial theory of development were used. To effectively complement these two theories, a social model of disability and a traditional model of disability were used.

\section{Statement Of The Problem}

Despite all the developments and changes in the education of persons with disabilities in Cameroon, there are still some limiting factors in children's social development particularly those with visual impairment. Children's connection with a given family, neighbourhood, centre or school limits opportunities for social development. Mixed age, sex, racial or cultural peer interactions is infrequent and early learned expectations, thereby limiting the extent of diversity in peer interaction. This is problematic as it hinders the effective personality development traits of visually impaired children. There is every reason to believe that the normal growth and development of children is dependent on the kinds of positive and negative experiences that children encounter during their infancy and childhood period. The degree of satisfaction of their basic needs' the depth of relationship between parents and children and rearing styles does form the foundations for the children's development. This is not always true when it comes to persons with disabilities.

There exists an inhumane discrimination among human creatures. It goes beyond mere discrimination when it comes to accepting persons with disabilities. Cultural perception and societal negative attitudes toward the visually impaired has a lot of influence on their personality development. The inhibition and consideration of children with disabilities as less humans accelerate negative peer interactions, peer rejection, isolation, anxiety, depression, substance abuse, and even suicidal ideation. This has also created in some children with visual impairments a pattern of absorption in solitary activities and hobbies; a pattern that is often difficult to change. It is against such negative cultural attributes and societal ill attitudes towards the visually impaired which often exert a lot of implication on their personality development the this study was proposed and carried out

Culturally imbedded concepts on disability affect the way in which they see themselves and the world around them. They also affect the way in which people around them such as members of their family, their community, and their society interact with them and they are the basis on which societies implement policies and programmes that directly and indirectly affect their right to play meaningful roles in their communities. These beliefs are not always negative. But whether positive or negative, it is necessary to understand them in order to effect change, either by addressing the negative models or by building on positive traditional models.

\section{OBJectives Of The STUdy}

\section{Main Objective}

The study examined the extent to which eco-cultural context impact personality development of children with visual impairment.

\section{Specific Objectives}

- To examine the relationship between parent-child interaction and self-esteem of children with visual impairments. 
Eco-Cultural Determinants and Personality Development of Children with Visually Impaired, Kumbo Central Sub-Division; North West Region of Cameroon

- To examine the influence of peer pressure on the self efficacy of children with visual impairments.

- To determine how cultural respect for disabilities influences personality development of children with visual impairments.

\section{Theoretical Reflections}

Table1.0. Major Theories/Models And Their Philosophies.

\begin{tabular}{|l|l|}
\hline MAJOR THEORIES USED & IT'S UNDERPINNINGS/PHILOSOPHIES \\
\hline $\begin{array}{l}\text { The Ecological theory of Urie } \\
\text { Bronfenbrenner (1917) }\end{array}$ & $\begin{array}{l}\text { Bronfenbrenner, proposed an ecological theory of development, he viewed the } \\
\text { individual as developing within a set of embedded contexts: the micro-system, } \\
\text { meso-system, exo-system and macro system. The upcoming child with visual } \\
\text { impairments is, therefore, easily influenced in acting according to the acceptable } \\
\text { social standards of the society within which he/she grows. }\end{array}$ \\
\hline $\begin{array}{l}\text { Erik Erikson's psychosocial } \\
\text { theory of development. }\end{array}$ & $\begin{array}{l}\text { Erikson conceives the life course as a series of building blocks, one influencing } \\
\text { the next as the individual grows progressively more or less capable of dealing } \\
\text { with life. He views development as a series of psychosocial crises requiring } \\
\text { resolution if an individual is to successfully move from one period to the next. }\end{array}$ \\
\hline $\begin{array}{l}\text { Social model of disabilities } \\
\text { (Abberley, 1987) }\end{array}$ & $\begin{array}{l}\text { social model of disability is founded upon the view that disability is 'something } \\
\text { imposed on top of disabled people's impairments through discrimination, } \\
\text { prejudice and exclusion from full participation in society' }\end{array}$ \\
\hline $\begin{array}{l}\text { Traditional model } \\
\text { disabilities (Seelman, 2004) }\end{array}$ & $\begin{array}{l}\text { Traditional model of disability is based on a cultural and/or religious } \\
\text { determination of knowledge, views and practices in a society in which disability } \\
\text { is associated with sin, shame, guilt and punishment? }\end{array}$ \\
\hline
\end{tabular}

\section{Conceptual Clarification}

Various concepts related to the phenomenon under study were reviewed. The concepts include: visual impairments, culture, personality development, parent child interaction, peer interaction, and social competence.

\section{Visual Impairments}

The visually impaired are those who have no vision at all or those who have some residual vision but cannot benefit maximally academically without some modifications in their educational materials, methods or educational environment. They include the blind, those with low vision and the partially sighted. There are two major ways of defining these groups: the legal definition and the educational definition. The legal definition is mainly used by the laymen and those in the medical profession. The legally blind are those who have visual acuity of 20/200 or less in the better eye even with corrections or have a field of vision so narrow that its widest diameter subtends an angular distance riot greater than 20 degrees (Hallahan and Kauffman, 2000). The normal visual acuity is 20/200 but for one who is legally blind, it means that what a person with normal vision will see at 200 feet distance the legally blind will see at 20 feet 'distance. Including the narrowed field Of vision in the legal definition indicates that one may have 20/200 .vision in the central field yet he/she may have severe restricted peripheral vision. The partially sighted according to the legal definition has a visual acuity ranging between 20/70 and 20/200 in the better eye with correction. On the other hand the educational definition is mainly used by educators and it relates to the educational functioning and provision needed by the child.

The blind according to Okeke (2001) are those who have been certified through all optical corrective measures that they have no sight and as such can neither read nor write the ordinary way. They therefore, require education by methods not involving the use of sight... Abosi and Ozoji (1985) refer to the blind as those who cannot read and write print after all optical corrective measures have been taken. From the above definitions it is evident that the blind will require modified teaching materials and methods in order to benefit maximally from the school curriculum. The blind, therefore, are those who have been certified to have complete loss of vision hence they cannot read nor write print. Rather they learn using braille and other means that do not involve the use of sight. Low vision is a term that emerge recently after Barrages findings in 1976. By this finding, not all people classified as people are really totally blind. Instead some of those formerly classified blind have some residual vision that 
can allow them see objects the near environment within a few inches or feet distance. Some people are classified as having low vision. Low vision refers those who have some residual vision that can enable them to see objects a few inches or feet away but cannot however, benefit maximally in academic work without some specialized attention methods and materials. Partial sight refers to people whose sight is poor but not so poor, to be classified as being blind. They can use their partial sight to carry out their day to day activities though they will need some adaptations in order to benefit from the school curriculum.

\section{Culture}

The term culture actually came into use during the middle ages. It derived from the Latin word for cultivation. Culture is the way of life of a social group and it includes actions, values and beliefs that can be communicated with necessary modifications from one generation to the succeeding one. Culture varies from one society to another and even within the same group of people depending on the period. This means that culture is not static but dynamic and it is expressed in terms of human behaviours, shared among a people and it is learn,

- Cultural aspects of human behaviour are not biologically or conditioned but are acquired solely through learning.

- Cultural conditioning of behaviour is ultimately accomplished through habituation and thus acts through unconscious process rather than rational deliberation, although secondary rationalizations are often offered to explain cultural values.

- All culture is equally developed according to their own proprieties and values; none is better, more advanced, or primitive than any other.

- Cultural traits cannot be classified or interpreted according to universal categories appropriate to "human nature".

They assume meaning only within the context of coherently interrelated elements internal to the particular culture under consideration (Chaudhuri, 1998).Therefore, culture is composed of everything symbol that we learn. All culture is learned, but not everything learned is culture. In fact, research has played a major role in establishing the relationship between culture and its effects upon human growth and development and of the effect of socio-economic and social-class influences upon children's learning. As a result, the anthropological meaning of the term "culture" embraces the way of life, the goals and the mores of people. The work scientists and educators in determining the relationship between culture and what a child will become has significant implications for the school. Each child must be considered in his particular social class and cultural environment. The motivation, growth, socialization of a child from the slums will differ radically from those of a child of the upper or middle class. In fact, a large number of children in our schools lack in their cultural environments, experiences upon which the school puts a premium: and motivation for school learning differs radically among children from different cultural environments. Also, the family life of children differs radically in different cultural environments. Below are some cultural aspect that guides the socialization and development of children within diverse cultures.

\section{VALUES}

Values are those aspects of cultural practices, actions or objects that are valued in high esteem in the society. The values of a society are also those aspects of the culture that society wants to preserve because their traditionally valued and they want to pass it from generation to generation. The values of the society are the aspect of the culture, which is needed in the society. These aspects of the culture that are valued should be passed from generation to generation so as to maintain a particular valid aspect of the culture. For instance, every society expects adults to get married for procreation to keep the society moving. An individual in the society may complain of inability to pay his children's school fees but will have money for marrying another wife to have more children or would provide money for the late father's burial. This is because the individual could place a higher premium on either having more children or spending a huge sum of money for the burial ceremony of his late father than paying the school fees of his surviving children. Values and judgments are not only important elements of culture but they are also relevant to modern society. 


\section{Beliefs, ROUTINES AND CUSTOMS}

Every culture has some beliefs which are accepted as true. These beliefs are sometimes called superstitious beliefs because of lack of empirical knowledge or lack of scientific proof. These beliefs are valued and so are accepted by majority of people in the community. For instance, the Isoko people of Delta State, Nigeria, believe that when an owl perches on the roof of a house, it portrays death. Also, the Yoruba believe that is a child sits at the entrance to a room when it is raining, thunder would strike the child. Routines and customs are also very important aspects of culture. Ezewu (1983) explained that three concept are interrelated - recipes, routines and customs. Recipes are the ideas and the understanding about how things should be done as prescribed by the culture in question. For instance, different societies have different ways prescribed by their culture in performing naming, burial, marriage ceremonies and so on. The above mentioned ceremonies are performed differently by Isoko, Urhobo and Ijaws of Delta State. The Hausa, Yorubas and Igbo perform their differently as no two societies are identical in terms of the culture of the people. Routines and customs refer to the actual doings and the regularities of those cultural actions or elements. Customs serve as recipes and routines to which people regularly resort for recurring purposes (Ezewu, 1983).

\section{Socialization}

Sociology is based on the precept that the human being is a social animal. But a newborn child is a biotic entity though not yet a social being. The curiosity is about how a human newborn rapidly transforms from a biological system to become a social being? The process by which the human organism is humanized into a social being or is transformed from its animal state into a mature social being or cultural agent is called socialization. Social interaction is at the centre of this process. By social interaction we mean the process of being aware of others when we act, of modifying our behaviour in accordance with consideration of others or their view of us. Social interaction occurs in Variety of ways and its patterns are complex, for instance, between people. Say husband and wife, siblings, classmates, peer group member\& acquaintances or strangers on the street, and among members of organizations or institutions. Socialization entails the learning of expectations, habits, values, beliefs, and other skills and requirements necessary for effective participation in social living. That is, socialization involves being taught all the things a child needs to increasingly function as a member of specific society: In this sense, socialization is "the process by which a individual becomes a member of a particular culture and takes on "values, beliefs, and other behaviours in order to function within it." It is through the process of socialization that society teaches desirable behaviour while inhibiting undesirable ones, prepares individuals to become successfully functioning members in its principal institutional settings or agencies such as the family, school, community, religion, and the workplace. Every society specifies certain outcomes or ranges of outcomes of socialization. For example, every society engages some of its resources to produce children who will be law-abiding and responsible adults.

Although much of this learning takes place in the first two or three of life within the family, socialization continues throughout life. Socialization is continuous - it is life long, starting as soon as the infant is born and continuing until death. It occurs through interaction with other humans. We could call these other humans partners or agents of socialization. For the newborn, the primary socialization agents are parents, who begin to communicate "correct" and expected modes of behaviour to him or her. Siblings and peers, especially within the neighbourhood peer culture, also become important socialization When we participate in peer group activities, attend school or move to a new place, or take a new job; or whenever we are a to make changes in beliefs, customs, norms, or behaviour (as adjustment to the HIV/AIDS pandemic calls for), additional socialization is necessary. Like many concepts in developmental psychology, socialization variously defined. One view of socialization is as the process by which an individual becomes a member of a particular culture and takes on itls value, beliefs and other behaviours in order to function within it. It could also be regarded as the process that "helps to explain how a person becomes capable of participating in society... (As well as) society is possible at all." It is through socialization that society teaches desirable behaviour while inhibiting undesirable attitudes and behaviour in a very real sense, socialization is something that emerges from thousands of exchanges between the child and family members spread out over a period of many years. During These exchanges, the child is altering the behaviour of the parent at the 
same time that the parent is presumably 'socializing' the child. It is this mutuality of effects that makes it very difficult to analyze cause and effect relations during socialization.

\section{Personality DeVelopMent}

The term personality connotes, variously, physical attractiveness, charm, good nature, case of manner, "outgoingness" or any other form of behaviour or attitude that induces a favourable impression. Every word or phase that indicates a way, in which an individual acts at a given situation, is a description of one aspect of personality. Personality is the "quality of individual's habits of thought and expression, his attitudes and interest, his manner of acting and his personal philosophy of life (Wood Worth, 1947).Personality involves the distinctive ways in which a person behaves, thinks and feels based on his or her cognition of self. A personality structure is derived from primary family care and values and from institutions in the culture that satisfy basic needs and tensions not met by primary care institutions. Personality stands for all the traits and characteristics which constitute a person including all physical capabilities, overt and covert behaviours, interests, values, conception of self, mentality, intelligence etc. Personality like concept of culture is a complex whole, having various traits. There is functional integration towards the whole as well as towards one another. According to Cuber (1959) defines personality as "the sum total of the observed or observable characteristics of a person". Personality is the individual's relatively distinct and consistent manner of perceiving, thinking, feeling, and behaving. This pattern of existence is sometimes used to infer the fundamental essence of the individual functioning in the physical, psychological, and social worlds.

The development of personality is conceived primarily as a process of learning which arises when the infant's innate behaviour repertoire is exposed to environmental circumstances. Personality and character develop chiefly during the impressive years. Everyone is born with heredity potential that is shaped and moulded by surroundings or culture. Heredity and environment both play a major part in the development of a person's total personality. Altitudes, habits and interest as well as character and conscience including the morals as spiritual ideas, standards life's values and modes of social expression are all integral parts of personality (Harris, 1995). The aspects of the existence of an individual are numerous, most of which are genetically determined and in the majority of cases, environment has a critical role in the completion of what nature has started. Personality and its changes over life span arc a good example on such phenomenon. Personality is defined as the distinguishing characteristics of an individual which differentiate him/her from others when displayed in a wide variety of situations and circumstances especially social ones (Council, 1985).

Cultural, racial, socioeconomic, educational, social guidance and health conditions could be environmental factors playing a critical role in personality development (Atkinson, 1996). Parental education, health and emotional states, social interactions are other factors which influence personality development. Several theories were staled explaining the development of personality, each of which dealt with the concept of personality development from a different point of view. The learning theory is another theory of personality development that is concerned mainly with child and his social background and which rose the idea of that behaviour is modified by experience (Theodore, 1983), The Psychoanalytic development theory was modified by Erik Eriksson and Stack Sullivan. The later emphasized the importance of interpersonal transactions between parents and child and the child's development in a social system. Erikson formulated eight stages of psychosocial development focusing upon the specific developmental tasks of each phase (psychosocial crisis). Generally, the life cycle is divided into eight developmental stages. These stages are: infancy, toddler hood, preschool child, school child, adolescence, young adulthood, middle years and old age.

\section{MeTHODOLOGY}

\subsection{Research Design}

The researcher used the descriptive survey design. The basic idea behind survey methodology is to measure variables by asking people questions and then to examine relationships among the variables. In most instances, surveys attempt to capture attitude or patterns of past behaviour. About the only options are whether to ask people questions once or over time. 
Eco-Cultural Determinants and Personality Development of Children with Visually Impaired, Kumbo Central Sub-Division; North West Region of Cameroon

\subsection{The Study Area}

This study was carried out in Kumbo central sub-division, the largest sub-division within Buidivision. Geographically, Bui Division is situated between latitudes $6^{\circ} 00^{\prime \prime}$ to $6^{\circ} 20^{\prime \prime}$ North of the Equator and longitudes $10^{\circ} 30^{\prime \prime}$ to $10^{\circ} 60^{\prime \prime}$ East of the Greenwich Meridian. It is a huge orographic plateau within the Cameroon Volcanic Line (CVL) with spectacular mountainous landscape like Mount Oku (3.011m above sea level) and the Mbaw-Tikar Plains (about 900rn above sea level) (Tume, 2008). The Division has a total surface area of 2,795 2 (Divisional Delegation of Lands, Bui, Kumbo), with Kumbo as its headquarters. It has six Sub Divisions namely: Kumbo Central $(630 \mathrm{~km} 2)$ which is the study area, Jakiri (675 km2), (375.3 2) Nkor-Noni (307.7 km2), Mbiarne (575 km2) and Elark-Oku (232 km2). Bui Division is bordered to the North by Donga and Mantung Division, to the North East by Boyo, East by Mentchum, South East by Ngoketunja, and finally in the South West by the Noun Division which is in the Western Region.

\subsection{Population of the Study}

Table1.1. Dynamics of Population in Bui Division

\begin{tabular}{|c|c|c|c|c|c|c|c|}
\hline Division & $\begin{array}{l}\text { Sub- } \\
\text { division }\end{array}$ & (1970) & (1976) & (1987) census & $\begin{array}{l}\text { (1998) } \\
\text { projections }\end{array}$ & $\begin{array}{l}(2005) \\
\text { projections }\end{array}$ & $\begin{array}{l}\text { (2015) } \\
\text { projections }\end{array}$ \\
\hline \multirow{5}{*}{ Bui } & Kumbo** & /I & /I & 93884 & 153995 & 210994 & 330862 \\
\hline & Mbven & II & II & 11952 & 16927 & 21123 & 28984 \\
\hline & Noni & /I & /I & 20331 & 23691 & 26112 & 30008 \\
\hline & Jakiri & // & // & 36315 & 57738 & 77555 & 118216 \\
\hline & Oku & /I & /I & 55582 & 78049 & 96870 & 131892 \\
\hline \multicolumn{2}{|l|}{ Total } & 118,000 & 151,821 & 218,064 & 330,400 & 431,664 & 632,428 \\
\hline
\end{tabular}

Kumbo central Sub-Division has been divided into 2 sub-divisions; Kumbo central sub-division and Nkum sub-division. Their population figures shall be considered as Kumbo Central Sub-Division

Source: Njilla, R.M.N. (2010).

The target population of the present study was made up of 400.000 inhabitants of Bui Division, (divisional delegation of social affairs). The study's accessible population was made up of all the 138 children with visual impairments in Kumbo central sub-division. From the accessible population, the sampled population was further determined from which the study's sample was finally drawn. The sampled population comprised of all the 66 students with visual impairments in the 5 selected schools considered in the study. Participants were young people aged 13 to 23 years; of both sexes (males and females); selected from 5 schools and were English speaking. They were either "residents" or "natives" (indigenes) of the locality in which they were found at the time of research. At the time of research, they were currently registered and attending identified schools.

Table1.2. The school type from which the sample size was drawn.

\begin{tabular}{|l|l|l|l|l|}
\hline School type & Number of schools & Male & Female & Total \\
\hline Special denominational schools & 1 & 29 & 14 & 43 \\
\hline Public inclusive schools & 2 & 9 & 4 & 13 \\
\hline Private inclusive schools & 2 & 6 & 4 & 10 \\
\hline Total & $\mathbf{5}$ & $\mathbf{4 4}$ & $\mathbf{2 2}$ & $\mathbf{6 6}$ \\
\hline
\end{tabular}

Table1.3. Summary of Respondent's Severity of Visual Loss.

\begin{tabular}{|l|l|l|l|l|}
\hline Summary of respondents severity of visual loss & Sex & \multirow{2}{*}{ Total } \\
\hline Category of condition & Number & Male & Female & \\
\hline Mild & 6 & 4 & 2 & $\mathbf{6}$ \\
\hline Moderate & 10 & 6 & 4 & $\mathbf{1 0}$ \\
\hline Severe & 16 & 10 & 6 & $\mathbf{1 6}$ \\
\hline Profound & 34 & 24 & 10 & $\mathbf{3 4}$ \\
\hline Total & $\mathbf{6 6}(\mathbf{1 0 0 \% )}$ & $\mathbf{4 4}$ & $\mathbf{2 2}$ & $\mathbf{6 6}$ \\
\hline
\end{tabular}




\subsection{Sample and Sampling Procedure}

This section describes the study's sample and the strategies that were used to select the representative elements from the accessible population, that is, the respondents, study sites and participating schools. The sample was made up of 66 children with visual impairment selected from an accessible population of 138 children with visual impairments within Kumbo central Sub-division (delegation of social affairs, Kumbo). The Baptist rehabilitation centre for the visually impaired was the vocal point for this study, reason being that all children with visual impairment in Kumbo Central -Sub Division usually begin their educational pursuits in the mention centre. Beside, the institution harbours a good resource centre and specialist in Braille and in mobility orientation. It is important to note that the Baptist rehabilitation centre for the visually impaired is the only centre with such facilities and experts, thus the 23 children identified in public and private inclusive schools acquired basic skills from the mentioned centre.

Table1.4. Distributions of the sample size by school

\begin{tabular}{|l|l|l|l|l|l|}
\hline \multirow{2}{*}{ Name of school } & \multicolumn{4}{|l|}{ Number of students } & \multirow{2}{*}{ Total } \\
\cline { 2 - 7 } & Male & $\mathbf{\%}$ & Female & $\mathbf{\%}$ & \\
\hline Baptist rehabilitation centre for the blind & 29 & $43.9 \%$ & 14 & $21.2 \%$ & 44 \\
\hline Government Bilingual High School Kumbo & 5 & $7.6 \%$ & 1 & $1.6 \%$ & 6 \\
\hline Chaffee Memorial secondary school Kumbo & 4 & $6.06 \%$ & 3 & $4.6 \%$ & 7 \\
\hline Baptist Primary School Kumbo & 2 & $3.03 \%$ & 3 & $4.6 \%$ & 5 \\
\hline City college kumbo & 4 & $6.06 \%$ & 1 & $1.6 \%$ & 5 \\
\hline Total & $\mathbf{4 4}$ & $\mathbf{6 6 . 7 \%}$ & $\mathbf{2 2}$ & $\mathbf{3 3 . 6 \%}$ & $\mathbf{6 6}$ \\
\hline
\end{tabular}

\section{INSTRUMENTATION}

The data for this study were collected using both primary and secondary techniques. Primary data were obtained using field techniques such as direct observation of various interactions and communication among the normal and the visually impaired, focus group discussions and interviews with both for children and parents of children with visual impairments. Also, questionnaires constituted the main source of primary data. it was designed based on the objectives of the study and the various indicators as well as indices deduced from the dependent and independent variables. In order to accelerate the administration and detailed analysis, the questionnaires which had both structured and unstructured items were divided according to various variables that the study aimed at investigating. Section A, was aimed at identifying the children, section B, aimed, at assessing parents interaction with their visually impaired children, section $\mathrm{C}$, focused on the assessment of respondents peer interaction considered as an important constituent of personality development, section D, aimed at assessing cultural perception of children with visual impairments as a step in determining how such perceptions can lead to either negative (bad) or positive (good) personality development. And section $\mathrm{E}$, which was only directed to parent of children with visual impairment aimed at deducing whether communication patterns and parenting of children with visual impairments is fused into their traditional belief. It should however be noted that data gotten from unstructured items was analyzed through content analysis which is a wide used qualitative technique. Due to respondents' visual impairments, questionnaires were brailed by a brailist. This was very important as the access and comfortability of respondents was the researchers' preoccupation. Focus group discussions were also used in the collection of data.

\section{Validity and Reliability of Instruments}

With the assistance of literature and expert researchers in the area of adolescence and personality development, content and construct validity were checked to address the appropriateness of the content, the comprehensiveness of the instruments, the logicality of the instrument in getting at the intended variables, the adequacy of the sample of items or questions in representing the complete content that was intended to be measured, and the appropriateness of the format of the instruments. At the start, the researcher developed the questionnaire himself, presented to his supervisor who thoroughly scrutinized indicating where and what to amend. Furthermore this same instruments were administered to similar respondent. To be sure of its validity, visually impaired children from the Bulu Centre were used for the validation process. Finally, terms which were not well understood were 
eliminated before the instrument was administered to the sample population for this study. An indepth focus group discussion was also conducted with 48 parents of children with and without visual impairments to establish their point of view with regard to the present study.. Interview data confirmed the constructs that were indicated in the questionnaire instrument. Reliability of the research instrument used for the current study was tested using the coefficient alpha (Cronbach's alpha). The reliability test for the components of the models is presented in Table 1.5

Table1.5. Reliability analysis

\begin{tabular}{|l|l|l|l|l|l|}
\hline $\mathbf{N}^{\mathbf{0}}$ & Sub -scale & $\mathbf{N}^{\mathbf{0}}$ item & $\mathbf{X}$ & S.D & $\begin{array}{l}\text { Cronbach's } \\
\text { Alpha*Reliability estimates }\end{array}$ \\
\hline 1 & Parent- child interaction & 7 & 18.38 & 3.89 & 0.81 \\
\hline 2 & Peer-child interaction & 5 & 12.18 & 2.03 & 0.71 \\
\hline 3 & Belief system and child dev't & 5 & 11.48 & 2.70 & 0.60 \\
\hline 4 & Child-teacher interaction & 6 & 17.26 & 2.47 & 0.87 \\
\hline
\end{tabular}

Components with Cronbach's Alpha equal or greater than 0.6 testify of a good internal consistency making them suitable for modelling. Generally, reliability is good when Cronbach's Alpha is greater than 0.5. Reliability analysis was computed and presented on Table 1.4. From the table, the Cronbach's Alpha computed for the variable, parent-child interaction against 7 items stood at $0.81>0.5$; that computed for the variable peer-child interaction against 05 items stood at $0.71>0.5$; that computed for the variable belief system and children personality development, against 7 items stood at $0.60>0.5$; that computed for the variable child-teacher interaction against 6 items stood at $0.87>0.5$. In all cases it was realized that Cronbach's Alpha was above 0.5, which indicated satisfactory internal consistency, thus making them suitable for modelling.

\section{Presentation Of Findings}

\subsection{Hypotheses Testing}

The chi square test was used to test Hypotheses stated at the beginning of the study in chapter one precisely.

\subsubsection{Hypothesis One}

$\mathrm{Ha}_{1}$ : There is a significant relationship between parent-child interaction and the quality of self-esteem exhibited by visually impaired children.

$\mathrm{Ho}_{1}$ : There is no significant relationship between parent-child interaction and the quality of selfesteem exhibited by visually impaired children.

The table below was used to test hypothesis one which stated that:

Table1.6. Parent-child interaction and self-esteem of visually impaired

\begin{tabular}{|l|l|l|l|l|l|}
\hline $\mathbf{S} / \boldsymbol{N}$ & Items & $\boldsymbol{x}^{2}$ & df & Asymp. Sig. & Dec \\
\hline 1 & My parents pray with me before and after bed period & 17.636 & 3 & 0.001 & $\mathrm{~A}$ \\
\hline 2 & My parents are ashamed of my condition & 11.212 & 3 & 0.011 & $\mathrm{R}$ \\
\hline 3 & We eat together on the same table with my parents & 9.394 & 3 & 0.024 & $\mathrm{~A}$ \\
\hline 4 & I converse freely at home with my parents & 22.970 & 3 & 0.000 & $\mathrm{~A}$ \\
\hline 5 & My parents do not care about what happens at school & 5.394 & 3 & 0.145 & $\mathrm{R}$ \\
\hline 6 & My father does not provide a good environment for us & 28.424 & 3 & 0.000 & $\mathrm{R}$ \\
\hline $\mathbf{7}$ & I crack jokes with my parents when I feel to & 8.303 & 3 & 0.040 & $\mathrm{~A}$ \\
\hline & Total & $\mathbf{1 0 3 . 3 3 3}$ & $\mathbf{2 1}$ & $\mathbf{0 . 2 2 1}$ & $\mathbf{A}$ \\
\hline
\end{tabular}

Since the calculated value $\left(x^{2}=103.333\right)$ is greater than the table value $\left(x^{2}=32.67\right)$ with $\mathrm{df}=21$ at $\mathrm{p} \leq$ 0.05 level of significance, we reject $\mathrm{Ho}_{1}$ and retain $\mathrm{Ha}_{1}$ which state that:

There is a significant relationship between parent-child interaction and the quality of self-esteem of visually impaired children. 
Eco-Cultural Determinants and Personality Development of Children with Visually Impaired, Kumbo Central Sub-Division; North West Region of Cameroon

\section{Hypothesis Two}

$\mathrm{Ha}_{2}$ : There is a significant relationship between peer interaction and the quality of self-efficacy of visually impaired children.

$\mathrm{Ho}_{2}$ : There is no significant relationship between peer interaction and the quality of self-efficacy of visually impaired children.

Table1.7. Peer pressure / interaction and self-efficacy of visually impaired

\begin{tabular}{|l|l|l|l|l|}
\hline S/N & Items & $\boldsymbol{x}^{2}$ & df & Asymp. Sig. \\
\hline 1 & My siblings feel so ashamed of my condition & 98.485 & 3 & 0.000 \\
\hline 2 & My friends mock at me in the neighbourhood & 48.545 & 3 & 0.000 \\
\hline 3 & Peers feel I am a person of worth at least on an equal plain & 48.545 & 3 & 0.000 \\
\hline 4 & Siblings feel I have nothing to be proud of. & 28.727 & 2 & 0.000 \\
\hline 5 & Siblings interact and converse with me at all times. & 24.788 & 3 & 0.000 \\
\hline & Total & $\mathbf{2 4 9 . 0 9}$ & $\mathbf{1 4}$ & $\mathbf{0 . 0 0 0}$ \\
\hline
\end{tabular}

Since the calculated value $\left(x^{2}=249.09\right)$ is greater than the table value $\left(x^{2}=23.68\right)$ with $\mathrm{df}=14$ at $\mathrm{p} \leq$ 0.05 level of significance, we reject $\mathrm{Ho}_{2}$ and retain $\mathrm{Ha}_{2}$ which postulated that:

There is a significant relationship between peer interaction and the quality of self-efficacy of visually impaired children.

\subsubsection{Hypothesis Three}

$\mathrm{Ha}_{3}$ : There is a significant relationship between cultural respect for disability and the quality of selfconcept of visually impaired children.

$\mathrm{Ho}_{3}$ : There is no significant relationship between cultural respect for disability and the quality of selfconcept of visually impaired children.

Table1.8. cultural respect for disabilities and self-concept of visually impaired

\begin{tabular}{|l|l|l|l|l|}
\hline $\mathbf{S} / \mathbf{N}$ & Items & $\boldsymbol{x}^{2}$ & Df & Asymp. Sig. \\
\hline 1 & My birth is a taboo to my culture & 35.091 & 3 & 0.000 \\
\hline 2 & Blindness is attributed to curse, anger from the gods etc & 26.455 & 2 & 0.000 \\
\hline 3 & Blind persons do not have any cultural rights to inheritance & 31.818 & 3 & 0.000 \\
\hline 4 & My culture accepts and appreciates me as a person & 74.242 & 3 & 0.000 \\
\hline 5 & $\begin{array}{l}\text { My tradition excludes blind persons from cultural ceremonies and } \\
\text { rituals. }\end{array}$ & 14.273 & 2 & 0.001 \\
\hline & Total & $\mathbf{1 8 1 . 8 7 9}$ & $\mathbf{1 4}$ & $\mathbf{0 . 0 0 1}$ \\
\hline
\end{tabular}

Since the calculated value $\left(x^{2}=181.879\right)$ is greater than the table value $\left(x^{2}=23.68\right)$ with $\mathrm{df}=14$ at $\mathrm{p} \leq$ 0.05 level of significance, we reject $\mathrm{Ho}_{3}$ and retain $\mathrm{Ha}_{3}$ which state that:

There is a significant relationship between cultural respect for disabilities and the quality of selfconcept of visually impaired children.

\section{FOCUSED GROUP DISCUSSION}

Data analysis consists of examining categorizing, tabulating and combining evidences, to address initial propositions of the study. The analysis was done by the researcher himself who acted as moderator. The analysis process began during the pre session. The moderator observed the level of familiarity between participants. It was observed that several people were relegated and well acquainted. The analysis was done in a sequence and efforts were made to make it systematic and verifiable. In addition efforts were made to filter out perceptions, expectations and personal opinions and tune into the signals briefing transmitted by participants of the focus groups discussion. Moreover, it was decided to analyze the discussion on the pattern of cross case analysis. This means 
grouping together the responses of all participants to particular questions. The following steps were taken in the process of data analysis.

A complete written summary soon after each interview was prepared. This; brief summary was compared with the few brief notes taken during the process of focus group interview. It served the purpose of debriefing session.

* The brief summary reports questioning route and demographic information about the participants were gathered.

* All the summaries were read in one sitting by the researcher and notes of potential trends and patterns relating to one question were made. Strongly held opinions and frequently held opinions were noted.

* As the last step of the data analysis the summary description, illustrative quotes and interpretations were prepared.

During the analysis consideration was also given to the factors like the word, the contexts, and the internal consistency, the specificity of responses and purpose of the reporting. Focus group interview was conducted in the main resource centre at the Baptist rehabilitation centre for the blind. Following questions were asked:

1) General views about the topic.

2) Major Socio Cultural Factors Affecting a Child's Personality Development

3) Effect of parent -child interaction, peer interaction.

4) Effect of Family Size on Personality Development

5) Effect of family structure on Personality development

6) The questions asked from the focus group were based on determining the views of parent of visually impaired children about the topic.

The discussion guide was prepared keeping in mind the objectives of the research and also to give the participants of focus group an opportunity to explicitly express their views about different socio cultural factors affecting child's personality development. In order to better ascertain the objectives of the study discussion was made with parents of visually impaired children from Upper, Middle and Lower income group participants. To conveniently and effectively conduct the focus group discussions, the researcher organized the discussion rather with parents, that is, both parents of children with visual impairment and those without children with visual impairments constituted the sample for the focus group discussion. Prior to the discussion sessions, the researcher solicited to parents who had attended an important social gathering at the rehabilitation centre for the blind. This gathering was aimed at improving on the quality of life and to address some attitudinal barriers as well as the needs of children with disabilities, (the preoccupation of the community). All attendants were free to make comments and freely shared their points of view.

\section{RECOMMENDATIONS}

The development of social competence must be a priority for children who are visually impaired, even those who appear to be developing typically. This topic is the mainstay of most of the parent's life and usually the major occupant of parent's thoughts in daily life. From the above mentioned findings of the study personality development of children are greatly influenced by socio - cultural factors, so there is a need to understand these factors i.e. how to manipulate these factors to bring positive change in the personality of children. Identification and knowledge of these factors can help the parents to take proactive steps in developing positive traits in child's personality. It is imperative for parents to determine the macro environment of children, which includes several social - cultural factors like parent's, their education level, family size, family structure, relatives, friends, schools, peers, clubs and many others with which children interact in their daily life. In light of this preamble and also considering the results of quantitative and qualitative research, following recommendations are made as an effort to improve the parent's endeavour of better personality development of their children: 
- Education plays a very vital role in personality development. It's usually said that knowledge creates a difference between a human being and animals. Therefore the more knowledgeable and educated the society is, the better will be the personality development of children. So it's very important for parents to give due consideration and importance to their children's education. Thus the education of visually impaired children should be a priority of all.

- Socialization of children is also an important factor, which needs to given due consideration parents. Children with greater number of friends exhibits more confidence and have good exposure than the children having smaller social circle. However, socialization also leads to some adverse impacts on children; therefore, good neighbourhood friendship should be enhanced by parent of visually impaired children.

- It is important for parent's to encourage their children with visual impairment to participate in extracurricular activities. Extracurricular activities inculcate multifarious traits amongst children. They learn to work in a team, have better opportunity to express them and sense of competition awakes, which lead them to put in maximum effort to develop a good personality. This is evident from results of the hypothesis that is also accepted that children involved in extracurricular activities exhibit better personality development.

- Schools can provide parents of children with visual impairments with information about childrearing skills, the importance of family support, child and adolescent development, and home contexts that enhance learning at each grade level. Teachers are an important contact point between schools and families. Teachers can become aware of whether the family is meeting the basic physical and health needs of the child. Effective communication with families about school programs and their child's progress is visible. This involves both school-to-home and home-toschool communication. Set up tunes for parent meetings that are convenient for them to attend.

- The problems that surround children with disabilities and their parents are generally wide in scope and complex in nature. This situation, among other measures, requires involvement of various bodies including the government, the non- government organizations and the community as whole.

- In the words of the participants, the government should focus on the education of children with disabilities, the home based education and support services (physical exercise, training on different skills, credit schemes) are also among the priorities. At the family level, there is a need for raising awareness of family to care for children with disabilities and to share the burden of the mothers. Training on early intervention particularly on child-parent interaction is essential. Training of teachers in Braille and in mobility was found to be among the serious problems particularly for children with visual impairment. This problem needs urgent intervention and solution. The parents with children with disabilities, particularly in severe cases, often undergo psychological crisis. The stress, frustration and hopelessness, shock, feeling of guilt were some of the problems reveals in the study. This, among other things, implies the need to consider counselling whenever services are planned for persons with disabilities. The counselling services are also to address various psychological problems with children.

\section{CONCLUSION REMARKS}

The purpose of this study was to determine whether the socio-cultural context has an impact on the personality development of visually impaired children in Kumbo Central-Sub Division. The findings of the study showed that parent-child interaction has a significant influence on children's self-esteem, socialization and performance. From the study majority of the parents assist their children as far as mobility exercises are concerned. The more they direct these children the better their self-esteem, selfefficacy and self-concepts improve positively. This assistance could not be achieved without effective communication. Most parents always discuss school related issues with their children and in the cause of doing so they become aware of their children's problems and their basic needs. The study also revealed that children who are provided with their school needs perform better than those without these basic school needs. That notwithstanding they were some few children who lacked some, of these school needs but they did better in school because of their assistance provided by special educators and the resource centre at the Baptist Rehabilitation Centre For the blind in Kumbo. Some 
children are born with a high Intelligent Quotient (IQ). However those who are provided with their school needs on time perform better in school. All these show that parental involvement in the socialization and learning process of their children should be encouraged so as to improve on children's academic performance.

Raising children with proper attention and care is highly valuable but challenging task for parents and families in general. This task becomes more challenging and at times threatening particularly in bringing up children with disabilities. It requires knowledge, skills, experience and a positive attitude on primarily of the part of the parents and care givers. It requires ability, commitment and hard work. The knowledge and ability to prevent or detect problems and intervene at an early age of the child is crucial. Failure to carry out any of these tasks for any reason leads to multiple of problems at different levels. Primarily, it worsens the situations of the children with disabilities. The problem becomes a threat to the parents and to the family as whole. Depending on the prevalence rate, the problem further affects the whole community. The results demonstrated the experiences of parents in raising children with disabilities. The efforts made by the parents, the support system available and the outcome were examined.

The results showed that the parents tried medication and as major strategies in seeking help for their children. Most of the parents suspected problems with their children at an early age. The parents were asked to tell the efforts made to find out the problems with the children. The results reveal that access to relevant information and services was the primary question of the parents. The parents tried different hospitals and Traditional medicine in seeking help for the children. Nonetheless, the efforts could not make any difference. The process of seeking for the help and the outcome were generally discouraging. Most of the parents were not able to get helpful information and service. The results show interplay of multiple of factors which were obstacles in the whole process. The parents, as shown in the results, experience series of problems in raising children with disabilities. The first groups of problems were concerning the general support system. The general support that could be tapped by the parents in the course of raising children with disabilities includes many things from different sources. Only three of these were examined in the present study. The first problem relates to the family as a system. The results reveal that families with children with visual impairments do not operate as a unit care for members with disabilities. In fact, the result showed that a significant proportion of the children in the sixty six families were living either with one parent only particularly with the mother or with the mother or with different relatives (sister, brother, grandparents, Aunts). Further examination of the relative role of family shows that the responsibility of caring for children with visual impairments was left mainly to the mothers. Other family members including fathers were less involved in giving care for children or adult members in the family. It appears the support system at a family level is poor. The support families get from the community appears either nil or poor. For instance,

\section{REFERENCES}

[1] Abraham, H. (1998) Parental perspectives on Mentally Retarded children: Improving the social Environment of Mentally retarded Children, FSCE

[2] Angel, R., L. Lein, J. Henrici, and E, Leventhal. 2001. "Health Insurance Coverage for Children and Then Caregivers in: Low-Income Urban Neighbourhoods." Policy Brief 01-2. Available oulinc: http://www.jhu. edu/ welfare/ 18581_WelfareBriefSummer0I .pdf

[3] Bandura, A. (2000). Social cognitive theory. In A. Kazdin (ed.) Encyclopaedia of Psychology. Washington, D.C., and New York: American Psychological Association and Oxford University Press.

[4] Bergeman, C.S., R. Plomin, G.E. McClearn and Pedersen, N.L., \& L.T. Frtberg. 1988. Genotypeenvironment interaction in personality development: Identical twins reared apart. Psychology and Aging, 3, 399-406.

[5] Bronfenbrenner, U. 1986. Ecology of the family as a context for Human Development: Research perspectives. Developmental Psychology. 22:723-742amre, B.K., and R.C. Pianta. 2001. Early teacherchild relationships and the trajectory of children's school outcomes through eighth grade. Child Development, 72(2):625-63

[6] Brown, B. B. (1990). Peer groups and peer cultures. In S. S. Feldman \& G. R. Elliott (Eds.), At the threshold (pp. 171-196). Cambridge, MA: Harvard University Press. 
[7] Buhrmester, D., \& Prager, K. (1995). In K. J. Rotenberg (Ed.), Disclosure processes in children and adolescents (pp. 10-56). New York: Cambridge University Press.

[8] Bukowski, W. M., \&Cillessen, A. H. (1998). Sociometry then and now: Building on six decades of measuring children's experiences with the peer group. San Francisco: Jossey-Bass.

[9] Coplan, R., \& Rubin, K. (1998). Exploring and assessing nonsocial play in the preschool: The development and validation of the preschool behaviour scale. Social Development, 7, 72-91.

[10] Coplan, R., Rubin, K., Fox, N., Calkins, S., \& Stewart, S. (1994). Being alone, playing alone, and acting alone: Distinguishing among reticence and passive and active solitude in young children. Child Development, 65, 129-137.

[11] Erwin, E. J. (1993). Social participation of young children with visual impairments in specialized and integrated environments. Journal of Visual Impairment \& Blindness, 87, 138-142.

[12] Ebster-Stratlon, C. 1984. Randomized trial of two parent-training programs for families with conductdisordered children. Journal of Consulting and Clinical Psychology, 52, 666-6

[13] Gresham, F. (1981). Social skills training with handicapped children: A review. Review of Educational Research, 51, 139-176.

[14] Guralnick, M., Connor, R., Hammond, M., Gottman, J., \& Kinnish, K. (1996a). Immediate effects of mainstreamed settings on the social interactions and social integration of preschool children. American Journal on Mental Retardation, 100, 359-377.

[15] Jones, R., \& Chiba, C. (1985). Social skills assessment and intervention (final report). Bethesda, MD: National Institute of Child Health and Human Development.

[16] Jones, R., Lavine, K., \& Shell, J. (1972). Blind children integrated in classrooms with sighted children: A sociometric study. New Outlook for the Blind, 66, 75-80.

[17] Kekelis, L. S, \& Sacks, S. Z. (1988). Mainstreaming visually impaired children into regular education programs: The effects of visual impairment on children's social interactions with peers. In S. Z. Sacks, L. S. Kekelis, \& R. J. Gaylord-Ross (Eds.), The development of social skills by visually impaired children (pp. 59-82). San Francisco: San Francisco State University.

[18] Kindermann, T.A. 1993. Natural Peer Groups as contexts for Individual Development: The case of children's motivation in school. Developmental Psychology. 29:970-977.

[19] Kochanska, G. 1997. Multiple pathways to conscience for children with different temperaments: From toddlerhood to age 5. Developmental Psychology, 33:228-240.

[20] La-Greca, A.M., \& N. Lopez. 1998. Social anxiety among adolescents: Linkages with peer relations and friendships. Journal of Abnormal Child Psychology, 26(2):83-94.

[21] MacCuspie, P. A. (1992). The social acceptance and interaction of visually impaired children in integrated settings. In S. Z. Sacks, L. S. Kekelis, \& R. J. Gaylord-Ross (Eds.), The development of social skills by blind and visually impaired students: Exploratory studies and strategies (pp. 83-102). New York: American Foundation for the Blind.

[22] MacCuspie, P. A. (1996). Promoting acceptance of children with visual disabilities: From tolerance to inclusion. Halifax, Nova Scotia: Atlantic Provinces Special Education Authority.

[23] McConnell, S., \& Odom, S. (1999). A multimeasure performance-based assessment of social competence in young children with disabilities. Topics in Early Childhood Special Education, 19(2), 67-74.

[24] Njilla, R.M.N. (2010). Management of Common Property Resources for Sustainable Rural Livelihoods in Bui Division, North West Region of Cameroon. Unpublished M.Sc. Thesis, Department of Geography, University of Buea. PP. 215.

[25] Nsamenang, A.B (1992c) Early Childhood Care and Education in Cameroon.In M.E Lamb et al (Eds), Day Care in context: socio-cultural perspectives. Hillsdale, NJ: EYbaum.

[26] Nsamenang, A.B (2005) African Culture, Human Ontogenesis with In C.B. Fisher and R.M Lerner (Eds), Encyclopaedia of Applied Developmental Science.

[27] Nsamenang, A.B \& M.E Lamb (1995). The force of beliefs: How the parental values of the Nso of North West Cameroon shape children's progress towards adult models.

[28] Odom, S., Zercher, C., Li, S., Marquart, J., \&Sandall, S. (1998, March). Social relationships of preschool children with disabilities in inclusive settings. Paper presented at the Conference on Research Innovations in Early Intervention, Charleston, SC.

[29] Odes, J.E., J.B. Grossman, and N.L. Resch. 2000. Agenis of change: Pathways through which mentoring relationships influence adolescents' academic adjustment. Child Development, 71(6): 1662-1671. 
Eco-Cultural Determinants and Personality Development of Children with Visually Impaired, Kumbo Central Sub-Division; North West Region of Cameroon

[30] Roche, K.M., D. Webster, C.S. Alexander and M.E. Ensminger. 1999. Neighbourhood effects on the association between parenting and youth fighting. Paper presented at the American Sociological Association 1999 Annual Meeting: Section on the Sociology of Children and Youth, Chicago, 1L.

[31] Rowe, D.C., J.L. Rodgers, and S. Meseck-Bushey. 1992. Sibling delinquency and the family environment: Shared and unshared influences. Child Development, 63(1):59-67.

[32] Rubin, K.H., and L. Rose-Krasnor. 1992. Interpersonal problem solving and social competence in children. In V. B. Van Hasselt \& M. Hersen (Eds.), Handbook of social development: A lifespan perspective (pp, 283-323). New York: Plenum Press.

[33] Rubin, K.H., R.S.L. Mills and L. Rose-Kransnor. 1989. Maternal beliefs and children's competence. In B. Schneider, G. Attili, Nadel and R. Weissberg (Eds.) Social competence in development perspective. Amsterdam: Kluwer Academic.

[34] Sacks, S. K., Kekelis, L. S., \& Gaylord-Ross, R. J. (Eds.). (1992). The development of social skills by blind and visually impaired students: Exploratory studies and strategies. New York: American Foundation for the Blind.

[35] Sparrow, S., Balla, D. A., \&Cicchetti, D. V. (1983). Vineland Adaptive Behaviour Scales (VABS). Circle Pines, MN: American Guidance Service.

[36] Tremblay, A., Strain, P., Hendrickson, J., \& Shores, R. (1981). Social interactions of normally developing preschool children: Using normative data for participant selection and target behaviour selection. Behaviour Modification, 5, 237-253.

[37] Schirm, V., K. Ross-Alaolmolki, and M. Conrad. 1995. Collaborative education through a foster grandparent program: Enhancing intergenerational relations. Gerontology \& Geriatrics Education, 15(3), 85-94.

[38] Sherif, M., O.J. Harvey, B.J. White, W.R. Hood and C.W. Sheiif. 1961. Intergroup Cooperation and Competition: The Robbers Cave experiment. Norman, OK: University Book Exchange.

[39] Silva, P.A. 1987. 4000 Otago Teenagers: A Preliminary Report from the Pathways to Employment Project. Dunedin: The Dunedin Multidisciplinary Health and Development Research Unit,

[40] Slomkowski, C, R. Rende, K.J. Conger, R.L. Simons and R.D. Conger. 2001. Sisters, brothers, and delinquency: Evaluating social influence during early and middle adolescence. Child Development 72(1):271-28

[41] St.Pierre, R.G., and J.I. Layzer 1998. Improving die the chances of children in poverty: Assumptions and what we have learned. Social Policy Report of the Society for Research in Child Development, 12(4):1-25

[42] Stocker, C, and J. Dunn. 1990. Sibling relationships in childhood: Links with friendships and peer relationships. British Journal of Developmental Psychology, 8, 227-244.

[43] Webster-Stratton, C. 1998. Preventing conduct problems in Head Start children: Strengthening parenting competencies. Journal of Consulting and Clinical Psychology, 66, 715-730.

[44] Yuh, E., \&Shey, P. (2008). The education of persons with special needs in Cameroon: A historical perspective. African Journal of Special Education, 1, 27-31.

Citation: Tani Emmanuel Lukong, Ph.D, Sr. Therese NyiaNjamfa, Ph.D, Nformi Doris Jaja. "Eco-Cultural Determinants and Personality Development of Children with Visually Impaired, Kumbo Central SubDivision; North West Region of Cameroon”. International Journal of History and Cultural Studies (IJHCS). vol 4, no. 1, 2018, pp. 90-109. doi:DOI: http://dx.doi.org/10.20431/2454-7654.0401007.

Copyright: (C) 2018 Authors. This is an open-access article distributed under the terms of the Creative Commons Attribution License, which permits unrestricted use, distribution, and reproduction in any medium, provided the original author and source are credited. 